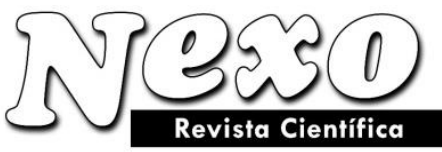

Vol. 34, No. 02, pp. 776-789/Junio 2021

\title{
Investigation of different SWCNTs interaction with dopamine and serotonin anticancers: a theoretical study
}

\section{Investigación de la interacción de diferentes SWCNT con anticancerosos de dopamina y serotonina: un estudio teórico}

\author{
Nastaran Saghayimarouf ${ }^{1}$, Majid Monajjemi ${ }^{2}$, Karim Zare*,1, Ali Shamel ${ }^{3}$ \\ ${ }^{1}$ Department of Chemistry, Science and Research Branch, Islamic Azad University, Tehran, Iran. \\ ${ }^{2}$ Department of Chemical Engineering, Central Tehran Branch, Islamic Azad University, Tehran, Iran. \\ ${ }^{3}$ Department of Chemistry, Ardabil Branch, Islamic Azad University, Ardabil, Iran. \\ k-zare@ srbiau.ac.ir
}

(recibido/received: 14-octubre-2020; aceptado/accepted: 27-enero-2021)

\begin{abstract}
Carbon nano tubes (CNTS) have two basic structure as single-walled and multi-walled based on hexagonal plexus of carbon atoms. CNTs can serve as platforms to conjugate other compounds specially in medications purposes by immobilization of biomolecules at their surface. Dopamine and serotonin are two biological molecules which have bifunctional activities as hormone and neurotransmitter. These two molecules have important roles as neurotransmitters in the central and peripheral nervous systems but serotonin functions as a mood regulator, while dopamine is connected to the "pleasure center". In this article we optimized molecular and structural properties of connected dopamine and serotonin with SWNTS with four different diameters $(7.0,7.5,7.7$ and $10.0 \mathrm{~nm})$ by using molecular quantum methods such as NMR shielding tensor data by B3LYP level of theory with 6-31 G(d) as a basis set, mk and frequency methods. Theoretical computations were performed to study NMR chemical shift data including magnetic shielding tensor $(\sigma$, $\mathrm{ppm}$ ), shielding asymmetry $(\eta)$, magnetic shielding anisotropy ( $\sigma a n i s o)$, magnetic shielding isotropy ( $\sigma$ iso) , skew of a tensor $(\mathrm{K})$ and chemical shift anisotropy $(\Delta \sigma)$ and span $(\Omega)$ at various rotation angles around a specific rotation, physical and chemical properties of atomic nuclei, frequency data by B3LYP/6-31g level of theory and POP method using gaussian 09 program.
\end{abstract}

Keywords: Dopamine, Serotonin, SWCNTs, NMR, Frequency.

\section{RESUMEN}

Los nanotubos de carbono (CNTS) tienen dos estructuras básicas como de pared simple y de pared múltiple basadas en plexos hexagonales de átomos de carbono. Los CNT pueden servir como plataformas para conjugar otros compuestos especialmente en medicamentos mediante la inmovilización de biomoléculas en su superficie. La dopamina y la serotonina son dos moléculas biológicas que tienen actividades bifuncionales como hormona y neurotransmisor. Estas dos moléculas tienen funciones importantes como neurotransmisores en los sistemas nerviosos central y periférico, pero la serotonina funciona como un regulador del estado de ánimo, mientras que la dopamina está conectada al "centro del placer". En este artículo optimizamos las propiedades moleculares y estructurales de la dopamina y la serotonina conectadas con SWNTS con cuatro diámetros diferentes $(7.0,7.5,7.7$ y $10.0 \mathrm{~nm})$ mediante el uso de métodos cuánticos 
moleculares como los datos del tensor de blindaje de RMN mediante el nivel de teoría B3LYP con 6-31 G (d) como conjunto de bases, mk y métodos de frecuencia. Se realizaron cálculos teóricos para estudiar los datos de desplazamiento químico de RMN, incluido el tensor de blindaje magnético $(\sigma, \mathrm{ppm})$, la asimetría de blindaje $(\eta)$, la anisotropía de blindaje magnético ( $\sigma a n i s o)$, la isotropía de blindaje magnético ( $\sigma$ iso), la desviación de un tensor $(\mathrm{K})$ y el desplazamiento químico anisotropía $(\Delta \sigma)$ y span $(\Omega)$ en varios ángulos de rotación alrededor de una rotación específica, propiedades físicas y químicas de los núcleos atómicos, datos de frecuencia por nivel de teoría B3LYP / 6-31g y método POP utilizando el programa gaussiano 09.

Palabras clave: Dopamina, Serotonina, SWCNT, RMN, Frecuencia.

\section{INTRODUCTION}

Dopamine is a medication form of a substance that occurs naturally in the body based on catecholamine and phenethylamine families and suppose to function both as a hormone and a neurotransmitter (Berridge, 2009). Also, it is known as feel good hormone as the secondary messenger system which sends messages between nerve cells in the braaccouin, binds to receptors in the brain and making them send signals from one cell to another and causes cellular changes that can affect your well-being in a number of ways for instant, in moments of pleasure and reward, we get a rush of dopamine, and when levels are too low, we feel a lack of motivation and feelings of helplessness (Romanelli, 2009; Robinson, 1993).

As Dopamine hormonal function can be mentioned as reduces of secretion of prolactin by stimulating theD2 receptors, thereby affecting milk production (Lindemann,2005) and also in memory consolidation, Dopamine or Dopamine agonists have critical role (Wise, 2004).

Abnormal dopamine levels (either too high or too low) are also linked to many pathological disorders, such as Schizophrenia, Tourette's syndrome, Parkinson's disease, Alzheimer's disease, Huntington's disease and Attention deficit hyperactivity disorder (ADHD) (Dickson, 2007; Howes, 2009; Miller, 2011).

Research also highlights that dopamine receptors are found in the kidneys, pancreas, lungs and blood vessels outside the central nervous system and belong to the large family of Heptahelical transmembrane spanning G protein-coupled receptors (GPCRs). By now five mammalian dopamine receptor subtypes have been identified and are classified into two major groups, the D1-like $\left(D_{1}\right.$ and $\left.D_{5}\right)$ which are mostly found in the cerebral cortex, hypothalamus, and thalamus and D2-like $\left(\mathrm{D}_{2}, \mathrm{D}_{3}\right.$, and $\left.\mathrm{D}_{4}\right)$ receptors which are similar in structure but differ by their affinity for dopamine and coupling to downstream effectors like G protein. Gprotein-coupled receptors also regulate the activity of PKB/Akt (protein kinase B) at serine-473 (Ser473) and threonine-308 (Thr308) although the mechanisms of these functions are poorly understood (Xiangdang, 2010). D3 and D4 receptors are less abundant and less widely distributed compared to $\mathrm{D}_{2}$ receptors (Romanelli,2009).

The contribution of dopamine receptor subtypes to increase of sensitization behavior in response to AMPH(Amphetamine) has been widely studied by blocking D1 and D2 receptors during repeated AMPH administration. These studies demonstrate an acute role for D1 receptors and D2 receptors as a supporting or secondary role in the development of AMPH sensitization (Vanderschuren, 2000).

Dopamine $\mathrm{D}_{1}$ or $\mathrm{D}_{2}$ receptor agonists despite of neurotrophin receptor stimulation, phosphorylate Akt at the Thr308 residue, not via phosphoinositide 3-kinase (PI3K), but via PKA (protein kinase A) and ERK (extracellular signal-regulated kinase) activation in primary striatal cultures (Brami-Cherrier,2002).

Studies show that Signaling through dopamine receptors adjust neurotic processes such as motoractivity, motivation and reward (including drug-seeking behavior), and highercognition (including working memory) (Kienast, 2006). 
Dopamine receptors are involved in all of the physiological functions of dopamine such as the autonomic movement, emotion, hormonal regulation, dopamine-induced immune effects, and tumor behavior, and etc. some evidences show that dopamine receptors are associated with the regulation of tumor behavior, including tumor cell death, proliferation, invasion, and migration which cannot only directly affect tumor behavior, but also limit tumor progress via activating tumor immunity (Wang, 2019).

Dopamine and Serotonin have important roles as neurotransmitters in the central and peripheral nervous systems (Deutch,1999) but serotonin functions as a mood regulator, while dopamine is connected to the "pleasure center.".

Serotonin [5-hydroxytryptamine (5-HT)] has an important role in many organs as a peripheral hormone transported by blood platelets and is released upon activation (Berger, 2009; Herr, 2017). This diverse functions of serotonin in the brain are mediated by multiple 5-HT receptor subtypes (15 known subtypes). These subtypes were at first classified based on pure pharmacological criteria ad belong to different families of 5-HT receptors (Peroutka, 1990).5-HT ${ }_{2}$ and 5- $\mathrm{HT}_{1 \mathrm{c}}$ are structurally similar and therefore have similar biochemical activation consequences and pharmacological profile (Conn, 1984; Conn, 1986; Hoyer, 1988). $5-\mathrm{HT}_{2}$ and $5-\mathrm{HT}_{1 \mathrm{c}}$ and the new discovered one $\left(5-\mathrm{HT}_{2 \mathrm{f}}\right)$ which lately renamed as $5-\mathrm{HT}_{2 \mathrm{~A}}, 5-\mathrm{HT}_{2 \mathrm{c}}$ and $5-\mathrm{HT}_{2 \mathrm{~B}}$ , demonstrated striking protection in their amino acid sequence, thus claimed that they could have evolved by mutation from a common ancestral gene (Julius, 1988).

As a neurotransmitter, serotonin participate in regulation of sleep, appetite, mood, and other important brain functions which cannot cross form blood-brain-barrier and needs transporter. Peripheral serotonin roles are the regulation of logical processes including cardiovascular function, bowel motility, ejaculatory latency, and bladder control, hemostasis, heart rate, intestinal motility, cell growth in liver, bone, and pulmonary arteries, and the development of heart, brain, and mammary gland and some addition roles in immunoregulatory functions including pro-inflammatory functions (Berger, 2009). Pro-inflammatory feature is now known that platelets ensure the targeted release of serotonin in platelet-activating environments like a thrombus or an inflammatory reaction (Wagner, 2008; Endo, 1997; Mössner, 1998).

Contrary to what has been said about the anti-inflammatory properties of serotonin, a specific activation of the 5-HT2A receptor subtype in primary aortic smooth muscle cells causes a superpotent inhibition of tumor necrosis factor (TNF)- $\alpha$-mediated inflammation (Yu, 2008; Herr, 2017).

Possible sources for peripheral serotonin are plasma, monocytes/macrophages, lymphocytes, vascular smooth muscle cells, adipocytes, mast cells (although human mast cells were long thought not to contain serotonin), and platelets (Herr, 2017).

Nanomaterials possess unique features which make them particularly attractive for biosensing applications.

Carbone nanotubes based on the number of walls, designed as single-walled carbon nanotube and multiwalled carbon nanotube. The side- walls of these tubes are made up of a hexagonal plexus, of carbon atoms, similar to graphene and are usually capped at both ends by one half of a fullerene-like molecule (Zhu, 2002; Tîlmaciu, 2015). Carbon nanotubes (CNTs) can be used as scaffolds for immobilization of biomolecules at their surface and best suited materials for the transduction of signals associated with the recognition of analytes, metabolites, or disease biomarkers due to their several exceptional properties such as physical, chemical, electrical, and optical characteristics properties. Besides CNTs can cross biological barriers including the cell membrane (Tîlmaciu, 2015; Pantarotto, 2004; Monajjemi,2019).

\section{Material and Methods}

Quantum mechanics (MQ)Calculations were performed using Gaussian 09 to study chemical and physical properties of nuclei (Reed, 1988; Monajjemi, 2020; Monajjemi, 2020). In this work, it has been mainly 
focused on optimized structures of combined Dopamine and Serotonin molecule with SWNTs with 7.0, 7.5, 7,7 and 10.0 nanometer diameter in NMR, POP=MK (Merz-Singh-Kollman) and freq methods.

Gaussian 09 uses numerical methods to find solutions to wave functions. Varies methods such as molecular orbital energies, bond energies, molecular geometries and energies, and vibrational frequencies, along with many other properties are appreciable by this program (Joohari, 2015; Naghsh, 2018; Monajjemi, 2020; Dang, 2020).

Nuclear magnetic resonance (NMR) typically utilizes a tuned resonance circuit with impedance matching to transmit power and receive signal (Hopper, 2011; Le, 2020; Pham, 2020; Monajjemi, 2020). Parameters optimized in NMR including magnetic isotropic ( $\sigma$ iso) and magnetic anisotropic ( $\sigma a n i s o)$ shielding, $\sigma_{11,} \sigma_{22}, \sigma_{33}$, atomic charges, asymmetry parameter $(\eta)$, chemical shift anisotropy $(\Delta \sigma)$ and span $(\Omega)$ as shown in the following result for its fundamental importance in chemistry and biochemistry studies (Facelli, 2002), in which calculated in GIAO magnetic shielding for Dopamine and Serotonin by using B3LYP method with 6-31G(d) basis set which gathered in table 1-2.

Charge transfer and electrostatic potential-derived also calculated using the Merz-Kollman-Singh (MK) charge distribution scheme obtained from B3LYP/6-31G (Besler, 1984; Le, 2019; Monajjemi, 2019; Monajjemi, 2019) as it shown in table 4-5.

Quantum chemistry calculations have been fulfilled to determine the partial charges on atoms. For this purpose, the Merz-Kollman-Singh (MK) algorithm (Singh, 1984; Menegon, 2002; Bultinck, 2002; Monajjemi, 2019; Le, 2019) was used, because of the fact, that MK charges are derived from the electrostatic potential, they are known to be much less basis dependent in comparison with the Mulliken charges.

Frequency methods with uff/6-31 G basis set has also been assessed by zero-point energy correction, enthalpy, and Gibbs free energy presented in table 3. The ideas of quantum zero-point energy may be used to measure forces arising in electromagnetism, nuclear physics, and pair theory (HBoyer, 2011; Monajjemi, 2019; Pham, 2019; Pham, 2019; Pham, 2019).

\section{RESULT AND DISCUSSIONR}

In this work the NMR parameters as Ab initio calculation of nuclear magnetic shielding such as $\sigma_{\text {iso }}$ (isotropy shielding) and $\sigma_{\text {aniso }}$ (anisotropy shielding), asymmetry parameter $(\eta)$, chemical shift anisotropy $(\Delta \sigma)$ and span $(\Omega)$ for some of the carbon atoms in Dopamine and Serotonin-SWCNT complex have been theoretically studied. the magnetic properties of atomic nuclei and physical and chemical properties of atoms have shown in table 1-2.

According to table 1, in complex Dopamine+7.0 (nm) diameter SWCNT the most value of $\sigma$ iso belongs to $\mathbf{C}_{111}$ (132.6) and $\mathbf{C}_{\mathbf{1}}$ has the most value of oaniso (431.1) and $\Omega$ (712.7), the most parameters of $\Delta \sigma$ are positive and the maximum specified in $\mathbf{C}_{25}(318.7)$. $\mathbf{C}_{54}$ has the maximum amount of $\eta$ (7.004), while The most content of etta $(\eta)$ are negative.

For Dopamine+SWCNT (7.5 nm diameter) most positive results described below:

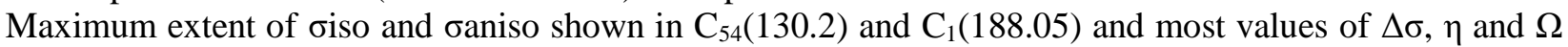
respectively belong to $\mathrm{C}_{41}(180.4), \mathrm{C}_{81}(1.46)$ and $\mathrm{C}_{15}(205.9)$. $\mathrm{C}_{7}$ in Dopamine combined $7.7(\mathrm{~nm}) \mathrm{SWCNT}$ has the two-minimum value of бiso and бaniso and the maximum amount of these two parameters respectively specified for $\mathrm{C}_{81}(148.1)$ and $\mathrm{C}_{71}$ (165.4). Among positive values of $\Delta \sigma$ and $\Omega$, most value is for $\mathrm{C}_{23}$ (125.5) and for $\mathrm{C}_{7}(184.5)$ and $\mathrm{C}_{1}$ has the most amount of $\eta$ (5.3) and in the end of table 1 , for medication connected to 10.0(nm)SWCNT $\mathrm{C}_{98}$ has the two maximum value of oiso and oaniso (2345.7 and 6599.9) and also $C_{7}$ has the two maximum value of $\Delta \sigma$ and $\Omega$ (5109.2 and 10365.9) and minimum value of $\sigma$ iso (3276.8). The $\Delta \sigma$ parameter of NMR for carbon atoms in dopamine are shown in Fig.1. 
Table 1. comparison of NMR chemical shielding tensors data calculated by B3LYP models with 6-31G (d) basis set for C atoms in Dopamine with 7.0,7.5,7.7,10.0 (nm)diameters SWCNT

\begin{tabular}{|c|c|c|c|c|c|c|}
\hline $\begin{array}{l}\text { Nanotube } \\
\text { diameter }\end{array}$ & $\begin{array}{c}\text { Atomic } \\
\text { label }\end{array}$ & $\sigma_{\text {Isotropic }}$ & $\sigma_{\text {Anisotropy }}$ & $\Delta \sigma$ & $\eta$ & $(\Omega)$ \\
\hline \multirow{17}{*}{$\begin{array}{l}7.0(\mathrm{~nm}) \\
\text { diameter }\end{array}$} & $\mathrm{Cl}$ & -61.9971 & 431.1205 & 125.94985 & -2.669681754 & 712.7136 \\
\hline & $\mathrm{C} 2$ & -55.9329 & 284.2069 & -262.72185 & -0.941227956 & 436.5767 \\
\hline & $\mathrm{C} 7$ & 70.2592 & 177.7319 & -16.77315 & -13.28529525 & 191.6289 \\
\hline & $\mathrm{C} 23$ & 51.2743 & 234.2899 & 231.56645 & -0.203828102 & 258.2786 \\
\hline & $\mathrm{C} 25$ & -28.7105 & 331.4964 & 318.79495 & -0.108449211 & 378.3108 \\
\hline & $\mathrm{C} 32$ & 80.1372 & 255.5227 & 219.06665 & 0.225399262 & 327.8285 \\
\hline & C37 & 54.7445 & 245.1959 & 105.19445 & 0.247925152 & 201.8405 \\
\hline & $\mathrm{C} 43$ & 49.6047 & 268.2065 & 225.15495 & -0.748621116 & 339.3801 \\
\hline & C54 & 56.7737 & 173.5293 & 9.6788 & 7.004473695 & 201.6148 \\
\hline & $\mathrm{C} 57$ & 56.1484 & 227.8706 & -138.54925 & -1.650464131 & 266.2388 \\
\hline & C65 & 62.4859 & 192.6591 & -100.0975 & -0.865877635 & 229.9987 \\
\hline & $\mathrm{C} 71$ & 60.3998 & 239.8636 & -62.51745 & -2.053075581 & 283.486 \\
\hline & $\mathrm{C} 81$ & 4.3217 & 287.7743 & 275.7912 & -0.883150731 & 391.8035 \\
\hline & $\mathrm{C} 92$ & 11.918 & 230.2496 & -61.76945 & -0.224433943 & 287.0529 \\
\hline & $\mathrm{C} 98$ & 63.308 & 235.2389 & -61.1212 & -5.883482327 & 257.8256 \\
\hline & $\mathrm{C} 105$ & 8.0629 & 275.3461 & 202.95535 & -0.711034296 & 320.4298 \\
\hline & C111 & 132.695 & 151.8513 & -54.41835 & 3.382608072 & 172.0154 \\
\hline \multirow{17}{*}{$\begin{array}{l}7.5(\mathrm{~nm}) \\
\text { diameter }\end{array}$} & $\mathrm{Cl}$ & 120.137 & 188.0531 & -57.725 & -3.683176859 & 197.5842 \\
\hline & $\mathrm{C} 7$ & 128.2401 & 174.4124 & -43.865 & -2.9666 & 186.6264 \\
\hline & $\mathrm{C} 15$ & 111.4445 & 151.1551 & 107.48605 & -1.15592163 & 206.9136 \\
\hline & $\mathrm{C} 23$ & 122.4577 & 183.9121 & 99.5384 & 0.51318 & 185.1918 \\
\hline & $\mathrm{C} 25$ & 128.9172 & 178.6165 & 119.7081 & 0.49403 & 187.0691 \\
\hline & $\mathrm{C} 32$ & 119.1856 & 187.3431 & 151.9811 & -0.129 & 179.4674 \\
\hline & $\mathrm{C} 36$ & 128.868 & 160.761 & 118.141 & 0.162187556 & 167.3685 \\
\hline & $\mathrm{C} 41$ & 125.2164 & 182.8736 & 180.45925 & -0.02099227 & 184.9352 \\
\hline & $\mathrm{C} 43$ & 127.3253 & 177.988 & 177.9551 & 0.22048 & 191.0786 \\
\hline & $\mathrm{C} 54$ & 130.2413 & 168.9081 & 90.9562 & 1.38125 & 190.2925 \\
\hline & $\mathrm{C} 57$ & 129.7138 & 172.4295 & 104.5858 & 0.57139 & 183.0504 \\
\hline & C65 & 126.7276 & 178.5838 & -15.0607 & -14.248 & 195.5395 \\
\hline & $\mathrm{C} 72$ & 130.9363 & 172.0715 & -30.44975 & -4.86461629 & 176.6094 \\
\hline & $\mathrm{C} 81$ & 120.7053 & 151.5337 & 115.9315 & 1.46449 & 200.2018 \\
\hline & $\mathrm{C} 92$ & 122.9333 & 175.8507 & 106.8202 & 0.43439 & 178.9967 \\
\hline & C105 & 127.371 & 153.9825 & 92.151 & 0.63219 & 183.2242 \\
\hline & C 125 & 126.3749 & 177.8 & 150.9622 & 0.55 & 182.91 \\
\hline \multirow{17}{*}{$\begin{array}{l}7.7(\mathrm{~nm}) \\
\text { diameter }\end{array}$} & $\mathrm{C} 1$ & 132.681 & 146.035 & -19.37495 & 5.300645937 & 184.2307 \\
\hline & $\mathrm{C} 4$ & 132.6676 & 146.0568 & 129.92095 & -0.04866998 & 184.3122 \\
\hline & $\mathrm{C} 7$ & 132.6689 & 145.9607 & 67.5803 & -1.610657248 & 184.5438 \\
\hline & $\mathrm{C} 15$ & 145.6092 & 155.7815 & -1.15065 & 52.35106244 & 163.5354 \\
\hline & $\mathrm{C} 25$ & 145.8312 & 155.7861 & -82.42945 & 1.099072601 & 163.2435 \\
\hline & $\mathrm{C} 32$ & 146.5872 & 163.0894 & -62.70495 & 1.13702746 & 169.048 \\
\hline & $\mathrm{C} 37$ & 146.6595 & 162.6306 & 35.988 & -1.72453318 & 168.1706 \\
\hline & $\mathrm{C} 43$ & 146.4216 & 160.8268 & 11.8748 & -5.0981406 & 170.6319 \\
\hline & C54 & 147.3921 & 160.0321 & 47.40945 & -1.1672831 & 170.1198 \\
\hline & C57 & 147.859 & 163.9497 & -72.37355 & 0.927175052 & 166.5406 \\
\hline & $\mathrm{C} 60$ & 147.9451 & 164.4014 & -62.739 & 1.797666523 & 167.5336 \\
\hline & C65 & 148.6659 & 162.816 & 41.80385 & -1.057312903 & 166.661 \\
\hline & C71 & 147.1292 & 165.4433 & 10.49405 & -8.11758568 & 169.1089 \\
\hline & $\mathrm{C} 81$ & 148.1237 & 164.0148 & -76.1874 & 1.058556927 & 167.1129 \\
\hline & $\mathrm{C} 92$ & 146.9118 & 157.0787 & -59.56625 & 1.506931358 & 166.234 \\
\hline & C105 & 143.9076 & 161.8892 & -54.40545 & 0.753313317 & 170.3449 \\
\hline & C 125 & 146.4518 & 155.0132 & 120.52035 & 0.009751465 & 163.0475 \\
\hline \multirow{17}{*}{$\begin{array}{l}10.0(\mathrm{~nm}) \\
\text { diameter }\end{array}$} & $\mathrm{C} 1$ & -1388.4138 & 2479.4789 & 2250.5794 & -2.875777125 & 4827.993 \\
\hline & $\mathrm{C} 2$ & -1310.1002 & 2359.1903 & 2182.0785 & -2.8750534 & 4602.4021 \\
\hline & $\mathrm{C} 7$ & -3276.8369 & 5221.9061 & 5109.2273 & -2.424260636 & 10365.904 \\
\hline & $\mathrm{C} 23$ & -943.2285 & 1794.2354 & 1770.62155 & -2.30857839 & 3436.1867 \\
\hline & $\mathrm{C} 25$ & -1450.956 & 2556.5532 & 2403.2284 & -2.411837277 & 4978.7921 \\
\hline & $\mathrm{C} 32$ & 585.6755 & 1286.1129 & -684.24555 & -2.516223671 & 1376.532 \\
\hline & $\mathrm{C} 41$ & -168.6885 & 709.2541 & 302.01865 & -3.17342803 & 1277.9586 \\
\hline & $\mathrm{C} 43$ & -459.1714 & 1080.7943 & 1073.9781 & -2.668578437 & 2087.1408 \\
\hline & C54 & 791.7969 & 1847.5768 & -856.0683 & -2.52629749 & 1921.9603 \\
\hline & $\mathrm{C57}$ & 1042.8053 & 2604.2729 & -1264.7287 & -2.530554318 & 2679.8707 \\
\hline & C65 & -362.4327 & 931.4973 & 759.3964 & -2.697498915 & 1711.1428 \\
\hline & $\mathrm{C} 71$ & 1990.6444 & 7995.2979 & -3678.92135 & -1.79392268 & 8893.8852 \\
\hline & $\mathrm{C} 81$ & -2438.9415 & 4738.534 & 3006.39335 & -3.282596608 & 8949.3709 \\
\hline & $\mathrm{C} 92$ & 1530.8075 & 4238.4856 & -1831.67415 & -2.603544495 & 4280.0077 \\
\hline & $\mathrm{C} 98$ & 2345.7545 & 6599.9016 & -3276.89115 & -2.31090732 & 6613.7541 \\
\hline & $\mathrm{C} 105$ & 143.0013 & 103.6263 & 73.80605 & 1.63769409 & 134.4928 \\
\hline & $\mathrm{C} 111$ & 33.602 & 361.0106 & 158.48845 & -1.765353416 & 599.3304 \\
\hline
\end{tabular}



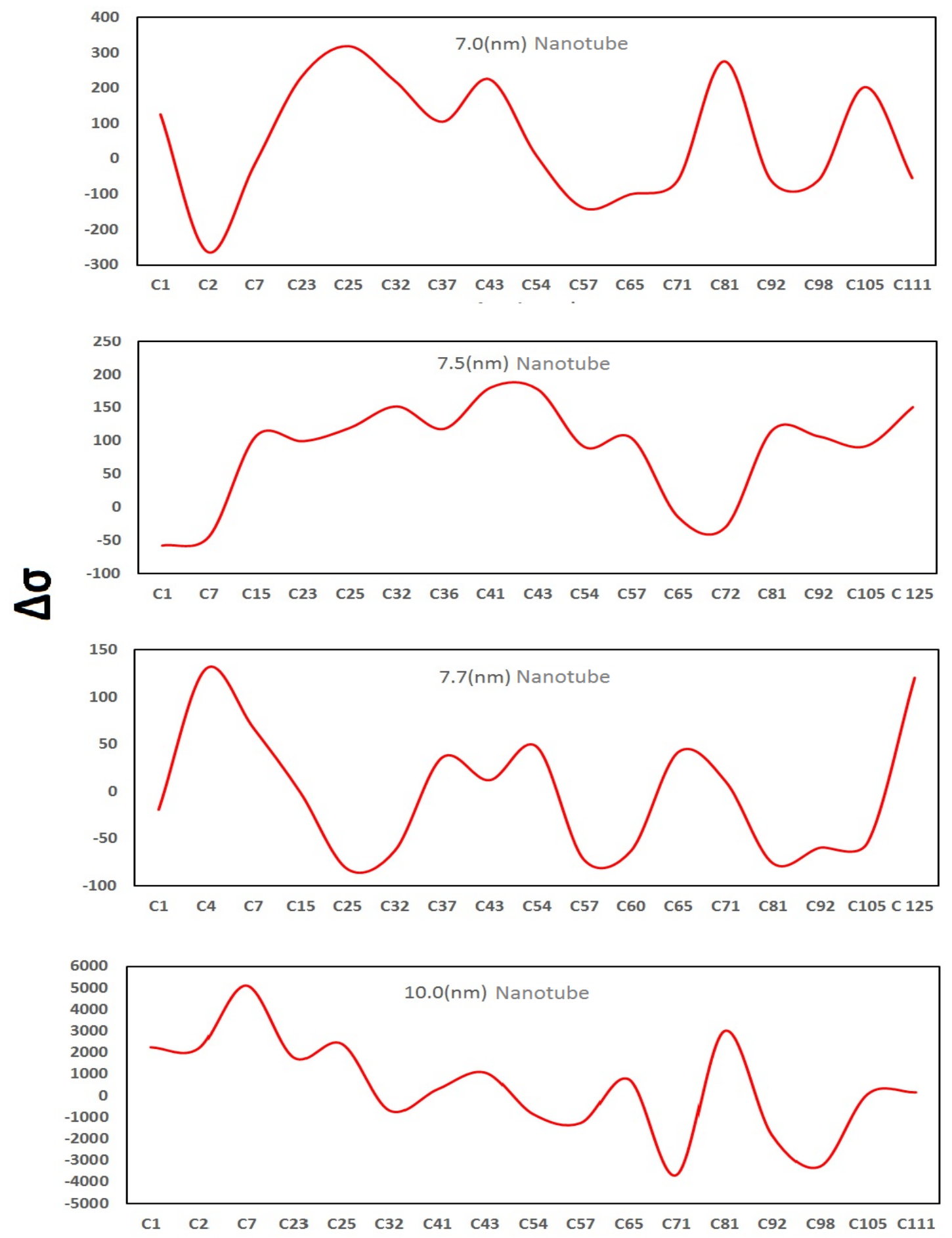

Atomic number

Fig. 1. $\Delta \sigma$ parameter of NMR; calculated by B3LYP models with 6-31G (d) basis set for C atoms in Dopamine with 7.0,7.5,7.7,10.0 (nm)diameters SWCNT 
Table 2. comparison of NMR chemical shielding tensors data calculated by B3LYP models with 6-31G (d) basis set for C atoms in Serotonin with 7.0,7.5,7.7,10.0 (nm)diameters SWCNT

\begin{tabular}{|c|c|c|c|c|c|c|}
\hline $\begin{array}{l}\text { Nanotube } \\
\text { diameter }\end{array}$ & Atomic label & $\sigma_{\text {Isotropic }}$ & $\sigma_{\text {Anisotropy }}$ & $\Delta \sigma$ & $\eta$ & $(\Omega)$ \\
\hline \multirow{17}{*}{$\begin{array}{l}7.0(\mathrm{~nm}) \\
\text { diameter }\end{array}$} & $\mathrm{C} 1$ & 116.4332 & 140.9858 & 82.8902 & -0.61646612 & 178.2112 \\
\hline & $\mathrm{C} 7$ & 74.2509 & 204.2218 & -96.43575 & -2.73489085 & 208.7471 \\
\hline & $\mathrm{C} 8$ & 71.6833 & 196.4182 & -110.11735 & -2.48652233 & 221.4184 \\
\hline & $\mathrm{C} 13$ & 6.6116 & 315.5116 & -99.4292 & -5.1722673 & 359.5881 \\
\hline & $\mathrm{C} 25$ & 28.3078 & 270.3146 & 250.47975 & 0.623975591 & 340.7136 \\
\hline & $\mathrm{C} 32$ & 12.9919 & 233.375 & -76.9656 & 2.2632059 & 356.2582 \\
\hline & C39 & 73.6444 & 230.0081 & 205.44545 & 0.679074421 & 272.3334 \\
\hline & $\mathrm{C} 43$ & 51.3202 & 205.3721 & -0.183834957 & -86.1022316 & -0.183834957 \\
\hline & C57 & 81.3243 & 177.24 & -62.7376 & -2.03901647 & 205.4642 \\
\hline & $\mathrm{C} 65$ & 58.7288 & 229.3421 & -0.8894 & 42.39566 & 258.2022 \\
\hline & $\mathrm{C78}$ & -84.8294 & 533.0753 & 329.9972 & 0.029666615 & 878.1523 \\
\hline & $\mathrm{C} 81$ & -5.0457 & 297.7524 & 290.15765 & -0.83964235 & 381.2771 \\
\hline & $\mathrm{C} 84$ & -2.4267 & 291.7623 & 169.5002 & -0.18012191 & 362.0305 \\
\hline & $\mathrm{C} 92$ & 75.3088 & 233.9536 & -72.7686 & -3.17459041 & 261.0028 \\
\hline & $\mathrm{C} 95$ & 10.1508 & 273.4406 & 58.50525 & 0.897727127 & 322.9286 \\
\hline & C105 & 32.7953 & 289.2982 & 137.56345 & 0.507050746 & 352.6472 \\
\hline & C111 & 150.8713 & 94.6607 & -27.1712 & 3.532291544 & 122.9843 \\
\hline \multirow{17}{*}{$\begin{array}{l}7.5(\mathrm{~nm}) \\
\text { diameter }\end{array}$} & $\mathrm{C} 1$ & 119.8483 & 188.1547 & -59.097 & -3.82773237 & 197.8378 \\
\hline & $\mathrm{C7}$ & 123.3916 & 181.7667 & -89.3649 & -1.96540924 & 185.6545 \\
\hline & $\mathrm{C} 14$ & 124.8865 & 172.9518 & -69.38185 & -2.45907179 & 182.0775 \\
\hline & $\mathrm{C} 25$ & 129.2678 & 177.9716 & -21.5596 & -7.29479675 & 187.0531 \\
\hline & $\mathrm{C} 27$ & 122.8933 & 184.2623 & 63.47605 & 1.704753998 & 190.7664 \\
\hline & $\mathrm{C} 32$ & 129.0051 & 159.1898 & 65.06915 & 1.247598132 & 178.1161 \\
\hline & $\mathrm{C} 43$ & 127.7431 & 177.1281 & 104.26365 & 0.855883618 & 190.7271 \\
\hline & $\mathrm{C} 49$ & 109.5641 & 174.7717 & 174.25285 & 1.067521995 & 242.5449 \\
\hline & C57 & 128.8224 & 178.6361 & 178.5107 & 0.073214099 & 183.8459 \\
\hline & C59 & 125.6289 & 180.4202 & 156.14745 & 0.112632963 & 184.7249 \\
\hline & C65 & 122.0102 & 149.8532 & 28.2208 & 5.905293259 & 195.7234 \\
\hline & $\mathrm{C} 70$ & 123.4886 & 181.3623 & 140.2931 & 0.333615124 & 187.5683 \\
\hline & $\mathrm{C} 81$ & 120.5973 & 151.6663 & 28.05075 & 8.245816957 & 200.4143 \\
\hline & $\mathrm{C} 87$ & 129.566 & 171.6776 & -18.73825 & -9.78194602 & 185.9051 \\
\hline & $\mathrm{C} 92$ & 129.026 & 175.6672 & -33.89155 & -4.33780249 & 178.8916 \\
\hline & C105 & 126.1465 & 180.6666 & -50.6156 & -3.3504058 & 182.7211 \\
\hline & C125 & 126.0951 & 177.9827 & 176.30285 & 0.043463563 & 183.2879 \\
\hline \multirow{17}{*}{$\begin{array}{l}7.7(\mathrm{~nm}) \\
\text { diameter }\end{array}$} & $\mathrm{C} 1$ & 160.0612 & 104.76 & -21.32715 & -3.61506108 & 126.6316 \\
\hline & $\mathrm{C} 7$ & 135.3304 & 138.025 & 35.07945 & -1.31414119 & 180.3636 \\
\hline & $\mathrm{C} 15$ & 148.1574 & 151.6621 & 6.21055 & -4.50489087 & 158.9513 \\
\hline & $\mathrm{C} 25$ & 145.6633 & 156.1608 & -82.45425 & 0.88012989 & 163.9731 \\
\hline & $\mathrm{C} 27$ & 145.5949 & 155.4306 & 152.84035 & 0.078529982 & 162.4718 \\
\hline & $\mathrm{C} 32$ & 146.6572 & 162.9422 & -63.17045 & 1.587151113 & 169.0624 \\
\hline & $\mathrm{C} 43$ & 150.5976 & 153.8898 & 14.02605 & -3.15836248 & 163.8515 \\
\hline & C51 & 146.212 & 161.7524 & 138.0016 & -0.06204276 & 171.7281 \\
\hline & C57 & 149.9806 & 163.0474 & -76.7552 & 1.16174409 & 167.4272 \\
\hline & $\mathrm{C60}$ & 148.4412 & 164.0148 & -61.9224 & 0.960626526 & 166.9198 \\
\hline & C65 & 147.0628 & 165.6413 & 39.7976 & -0.94253171 & 167.4507 \\
\hline & $\mathrm{C} 81$ & 148.0398 & 164.5705 & -75.8767 & 1.309603607 & 167.5875 \\
\hline & $\mathrm{C} 92$ & 146.5586 & 161.5587 & -65.5776 & 1.027086993 & 169.8241 \\
\hline & C99 & 146.7288 & 162.3846 & 2.89865 & -23.8520518 & 168.7669 \\
\hline & $\mathrm{C} 105$ & 146.6955 & 163.0194 & -66.23605 & 1.453032752 & 168.4526 \\
\hline & C106 & 146.5392 & 163.5071 & -57.88785 & 1.397715583 & 168.953 \\
\hline & C125 & 145.583 & 156.0022 & 122.8915 & -0.0398034 & 163.6274 \\
\hline \multirow{17}{*}{$\begin{array}{l}10.0(\mathrm{~nm}) \\
\text { diameter }\end{array}$} & $\mathrm{C} 1$ & 19.582 & 235.182 & -111.68145 & -1.76457908 & 283.3032 \\
\hline & $\mathrm{C} 4$ & 521.7316 & 1059.7161 & -473.89885 & -3.2537244 & 1096.9219 \\
\hline & $\mathrm{C} 7$ & 870.3555 & 2098.6893 & -1075.0815 & -2.82456744 & 2136.5468 \\
\hline & $\mathrm{C} 8$ & 630.2476 & 1385.0651 & -653.74295 & -3.07860291 & 1417.3609 \\
\hline & $\mathrm{C} 14$ & 227.4063 & 219.4072 & -18.5734 & -15.2379694 & 275.3438 \\
\hline & $\mathrm{C} 25$ & 422.5754 & 734.9325 & -425.0484 & -2.36265305 & 805.3255 \\
\hline & $\mathrm{C} 32$ & 133.2455 & 196.3262 & 130.8842 & 0.9977 & -177.462464 \\
\hline & $\mathrm{C} 43$ & 263.358 & 257.8087 & -53.5824 & -8.09252665 & 330.6118 \\
\hline & C57 & -31.7412 & 426.6604 & 327.10215 & -2.68408768 & 695.9907 \\
\hline & C65 & 251.2293 & 230.0311 & -183.1533 & -1.49321798 & 304.3239 \\
\hline & C69 & 247.0161 & 218.8922 & -40.4807 & -9.77402812 & 294.7551 \\
\hline & $\mathrm{C} 73$ & -104.0341 & 534.4774 & 494.7451 & -2.33363504 & 911.4645 \\
\hline & $\mathrm{C} 81$ & 178.5111 & 102.888 & -114.6782 & 0.740612427 & 147.1954 \\
\hline & $\mathrm{C} 92$ & -269.4006 & 722.5244 & 661.7302 & -3.02345034 & 1372.9567 \\
\hline & C94 & -485.1518 & 1031.7152 & 1005.4664 & -2.78605809 & 1990.3419 \\
\hline & $\mathrm{C} 105$ & 156.9733 & 89.7987 & 71.9148 & 0.848958768 & 118.8076 \\
\hline & $\mathrm{C} 111$ & 152.9726 & 106.1711 & 81.5342 & -0.63634769 & 130.6261 \\
\hline
\end{tabular}


As it shown in table 2, in Serotonin $+7.0(\mathrm{~nm})$ SWCNT complex, $\mathrm{C}_{1}$ has the most value of $\sigma$ iso (116.4) and the most value of $\sigma$ aniso, $\Delta \sigma$ and $\Omega$ demonstrated in $C_{78}$ which respectively equals with 533.07,329.9 and 787.1 and $\mathrm{C}_{65}$ has the most value of $\eta$ (42.3). In Serotonin+7.5 nm diameter SWCNT complex, the maximum level of oiso and бaniso respectively belongs to $\mathrm{C}_{87}(129.5)$ and $\mathrm{C}_{1}(188.1)$ and the minimum level belongs to $C_{49}(109.5)$ and $C_{65}(149.8)$ and also the maximum level of $\Delta \sigma$ and $\Omega$ are respectively 187.5 and 242.5 which belongs to $\mathrm{C}_{57}$ and $\mathrm{C}_{42}$. Most of the etta $(\eta)$ parameters have been reported positive and the maximum value belongs to $\mathrm{C}_{81}(8.2) . \mathrm{C}_{1}$ in drug+7.7(nm)diameter SWCNT has the two maximum and minimum value of $\sigma$ iso (160.01) and бaniso (104.7) and the minimum value of $\sigma$ iso (135.3) and maximum value of $\Omega(242.5)$ also belongs to $C_{7}$. As it specified in these results, the most value of $\sigma$ aniso, $\Delta \sigma$ and $\eta$ are for $C_{65}(165.6)$, $\mathrm{C}_{27}(152.8)$ and $\mathrm{C}_{32}$ (1.58). $\mathrm{C}_{7}$ in Serotonin connected to SWCNT (10.0nm diameter) has the most value of

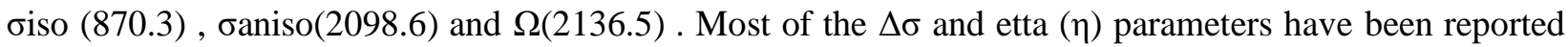
negative and the maximum values belong to $\mathrm{C}_{94}(1005.4)$ and $\mathrm{C}_{32}(0.9)$. The $\eta$ parameter of NMR for carbon atoms in serotonin are shown in Fig.2.
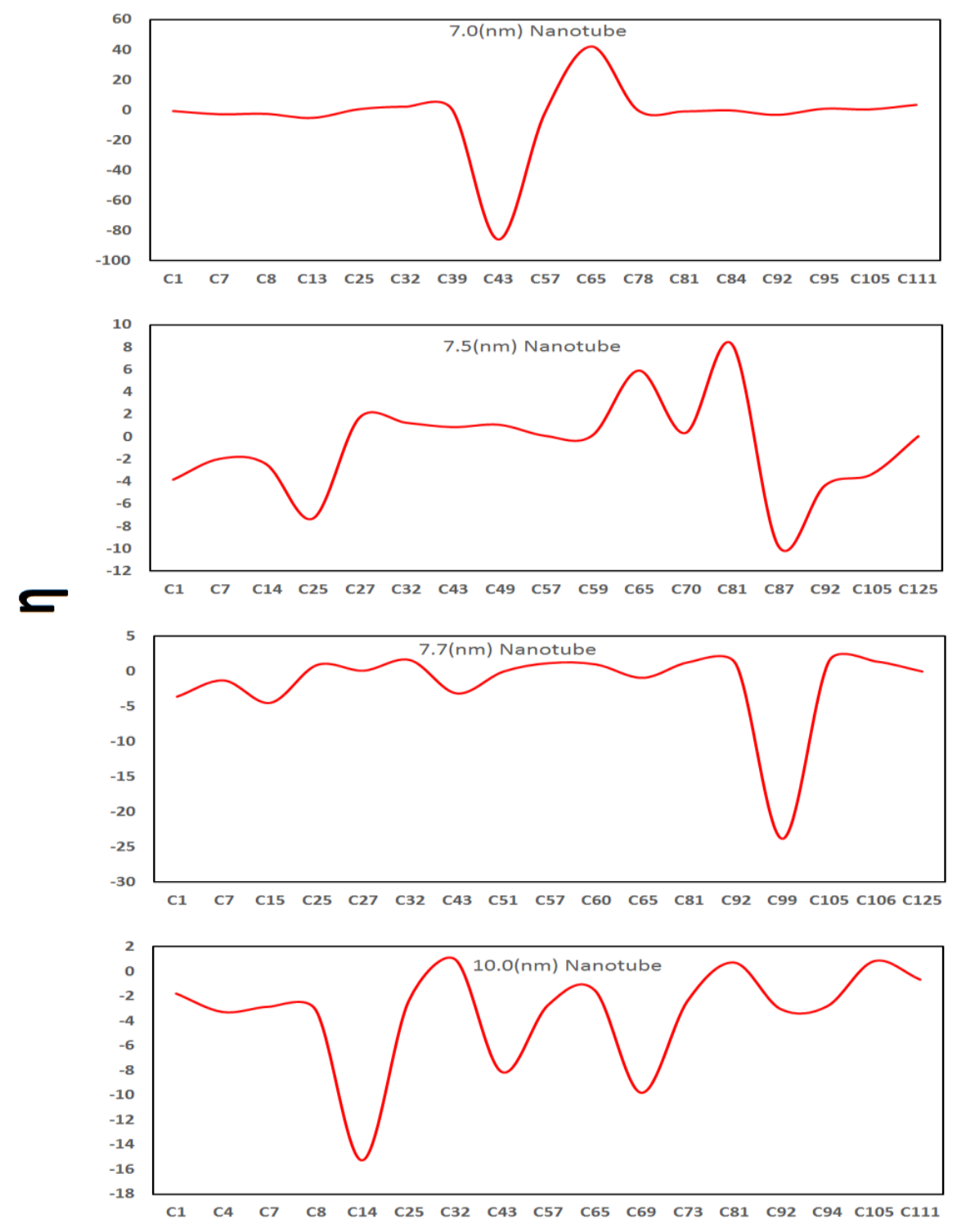

Atomic number

Fig.2. $\eta$ parameter of NMR; calculated by B3LYP models with 6-31G (d) basis set for C atoms in Serotonin with 7.0,7.5,7.7,10.0 (nm)diameters SWCNT 
Thermodynamic paraeters including zero-point energy, total energy, enthalpies $(\Delta \mathrm{H})$ and Gibbs free energy $(\Delta \mathrm{G})$ of the complex were computed by Freq method using Uff/6-31G(d) obtained and summarized in table3. Also, we can comparison atom charge distributions in MK method for the two-molecule complex in table 4-5.

Table 3. Zero-point energy, total correction energy, enthalpy and free gibs energy analysis of B3LYP method in uff/6-31G basis set

\begin{tabular}{|c|c|c|c|c|c|c|c|c|}
\hline & $\begin{array}{c}7,0- \\
\text { dopamine }\end{array}$ & $\begin{array}{c}7,0- \\
\text { serotonin }\end{array}$ & $\begin{array}{c}7,5- \\
\text { dopamine }\end{array}$ & $\begin{array}{c}7,5- \\
\text { serotonin }\end{array}$ & $\begin{array}{c}7,7- \\
\text { dopamine }\end{array}$ & $\begin{array}{c}7,7- \\
\text { serotonin }\end{array}$ & $\begin{array}{c}10,0- \\
\text { dopamine }\end{array}$ & $\begin{array}{c}10,0- \\
\text { serotonin }\end{array}$ \\
\hline$E_{Z P E}$ & 1.134665 & 1.164751 & 1.772866 & 1.804665 & 1.737421 & 1.774504 & 1.296485 & 1.329319 \\
\hline$E_{\text {tot }}$ & 1.186675 & 1.216071 & 1.830497 & 1.863011 & 1.787204 & 1.823544 & 1.331974 & 1.364415 \\
\hline$H_{\text {corr }}$ & 1.187619 & 1.217015 & 1.831441 & 1.863955 & 1.788148 & 1.824488 & 1.332918 & 1.365359 \\
\hline$G_{\text {corr }}$ & 1.062814 & 1.096034 & 1.698319 & 1.729044 & 1.663745 & 1.703395 & 1.236122 & 1.270746 \\
\hline$E_{0}=\varepsilon_{0}+E_{\text {ZPE }}$ & 4.044015 & 4.050447 & 5.691152 & 7.530773 & 4.684883 & 4.841821 & 3.870821 & 3.950483 \\
\hline$E=\varepsilon_{0}+E_{\text {tot }}$ & 4.096024 & 4.101766 & 5.748783 & 7.589119 & 4.734665 & 4.89086 & 3.90631 & 3.985579 \\
\hline$H=\varepsilon_{0}+H_{\text {corr }}$ & 4.096968 & 4.102711 & 5.749727 & 7.590063 & 4.735609 & 4.891804 & 3.907254 & 3.986523 \\
\hline$G=\varepsilon_{0}+G_{\text {corr }}$ & 3.972163 & 3.98173 & 5.616606 & 7.455152 & 4.611206 & 4.770712 & 3.810458 & 3.89191 \\
\hline
\end{tabular}

Table4.Merz-Kollman parameters analyses of Dopamine+SWCNT carbon atoms in BLYP3/3-61(d) level of theory

\begin{tabular}{|c|c|c|c|c|c|c|c|}
\hline \multicolumn{4}{|c|}{ Dopamine $+7.0 \mathrm{~nm} \mathrm{SWCNT}$} & \multicolumn{4}{|c|}{ Dopamine $+7.5 \mathrm{~nm} \mathrm{SWCNT}$} \\
\hline Atomic label & $\Delta \mathrm{V}=(\mathrm{V} 2-\mathrm{V} 1)$ & $\Delta q$ & $\Delta \mathrm{V}=(\mathrm{k}(\mathrm{q} 2-\mathrm{q} 1) / \mathrm{R} 21)$ & Atomic label & $\Delta \mathrm{V}=(\mathrm{V} 2-\mathrm{V} 1)$ & $\Delta q$ & $\Delta \mathrm{V}=(\mathrm{k}(\mathrm{q} 2-\mathrm{q} 1) / \mathrm{R} 21)$ \\
\hline $\begin{array}{l}\text { Atom92- } \\
\text { Atom 2 }\end{array}$ & -0.02807 & 0.131906 & $4.68363 \mathrm{E}+18$ & $\begin{array}{l}\text { Atom 41- } \\
\text { Atom 25 }\end{array}$ & -0.000616 & 0.002743 & $1.75796 \mathrm{E}+17$ \\
\hline $\begin{array}{l}\text { Atom76- } \\
\text { Atom62 }\end{array}$ & -0.022281 & 0.021203 & $7.48639 \mathrm{E}+17$ & $\begin{array}{l}\text { Atom 111- } \\
\text { Atom 45 }\end{array}$ & 0.005974 & 0.000326 & $3.64132 \mathrm{E}+15$ \\
\hline $\begin{array}{l}\text { Atom90- } \\
\text { Atom88 }\end{array}$ & -0.005501 & -0.006014 & $-3.56063 \mathrm{E}+17$ & $\begin{array}{l}\text { Atom 72- } \\
\text { Atom } 56\end{array}$ & -0.002334 & -0.003544 & $-2.26055 \mathrm{E}+17$ \\
\hline $\begin{array}{l}\text { Atom71- } \\
\text { Atom54 }\end{array}$ & 0.010647 & -0.011558 & $-3.7709 \mathrm{E}+17$ & $\begin{array}{l}\text { Atom 118- } \\
\text { Atom 53 }\end{array}$ & 0.002178 & 0.000472 & $5.17041 \mathrm{E}+15$ \\
\hline $\begin{array}{l}\text { Atom86- } \\
\text { Atom70 }\end{array}$ & 0.006281 & -0.022734 & $-1.51919 \mathrm{E}+18$ & $\begin{array}{l}\text { Atom 63- } \\
\text { Atom } 62\end{array}$ & 0.000793 & 0.001372 & $8.75176 \mathrm{E}+16$ \\
\hline $\begin{array}{l}\text { Atom37- } \\
\text { Atom35 }\end{array}$ & 0.014977 & 0.139343 & $8.25474 \mathrm{E}+18$ & $\begin{array}{l}\text { Atom 102- } \\
\text { Atom } 70\end{array}$ & 0.001731 & -0.000655 & $-1.01306 \mathrm{E}+16$ \\
\hline $\begin{array}{l}\text { Atom98- } \\
\text { Atom23 }\end{array}$ & -0.004162 & -0.147796 & $-2.89676 \mathrm{E}+18$ & $\begin{array}{l}\text { Atom 148- } \\
\text { Atom 22 }\end{array}$ & -0.005766 & -0.003312 & $-1.23162 \mathrm{E}+17$ \\
\hline $\begin{array}{l}\text { Atom79- } \\
\text { Atom77 }\end{array}$ & -0.007455 & -0.065044 & $-3.82505 \mathrm{E}+18$ & $\begin{array}{c}\text { Atom 131- } \\
\text { Atom } 36\end{array}$ & 0.004748 & 0.011702 & $1.42561 \mathrm{E}+17$ \\
\hline $\begin{array}{l}\text { Atom81- } \\
\text { Atom37 }\end{array}$ & -0.003872 & -0.084847 & $-1.27372 \mathrm{E}+18$ & $\begin{array}{l}\text { Atom 61- } \\
\text { Atom } 46\end{array}$ & 0.002981 & 0.001505 & $9.59932 \mathrm{E}+16$ \\
\hline $\begin{array}{l}\text { Atom87- } \\
\text { Atom85 }\end{array}$ & -0.01285 & 0.003761 & $2.20294 \mathrm{E}+17$ & $\begin{array}{l}\text { Atom 32- } \\
\text { Atom15 }\end{array}$ & -0.00244 & 0.003913 & $2.49531 \mathrm{E}+17$ \\
\hline \multicolumn{4}{|c|}{ Dopamine $+7.7 \mathrm{~nm}$ SWCNT } & \multicolumn{4}{|c|}{ Dopamine $+10.0 \mathrm{~nm}$ SWCNT } \\
\hline Atomic label & $\Delta \mathrm{V}=(\mathrm{V} 2-\mathrm{V} 1)$ & $\Delta \mathrm{q}$ & $\Delta \mathrm{V}=(\mathrm{k}(\mathrm{q} 2-\mathrm{q} 1) / \mathrm{R} 21)$ & Atomic label & $\Delta \mathrm{V}=(\mathrm{V} 2-\mathrm{V} 1)$ & $\Delta \mathrm{q}$ & $\Delta \mathrm{V}=(\mathrm{k}(\mathrm{q} 2-\mathrm{q} 1) / \mathrm{R} 21)$ \\
\hline $\begin{array}{l}\text { Atom100- } \\
\text { Atom94 }\end{array}$ & 0.00108 & 0.001508 & $1.00785 \mathrm{E}+17$ & $\begin{array}{l}\text { Atom 52- } \\
\text { Atom 50 }\end{array}$ & -0.00021 & -0.002201 & $-3.87102 \mathrm{E}+16$ \\
\hline $\begin{array}{l}\text { Atom 38- } \\
\text { Atom31 }\end{array}$ & 0.000015 & -0.000244 & $-1.62382 \mathrm{E}+16$ & $\begin{array}{l}\text { Atom 39- } \\
\text { Atom 23 }\end{array}$ & 0.001707 & -0.001737 & $-2.18651 \mathrm{E}+16$ \\
\hline $\begin{array}{l}\text { Atom 86- } \\
\text { Atom79 }\end{array}$ & 0.000709 & 0.000327 & $2.18433 \mathrm{E}+16$ & $\begin{array}{c}\text { Atom 29- } \\
\text { Atom 19 } \\
\end{array}$ & 0.000105 & 0.015327 & $1.02405 \mathrm{E}+18$ \\
\hline $\begin{array}{l}\text { Atom 37- } \\
\text { Atom15 }\end{array}$ & -0.000669 & 0.008765 & $5.84167 \mathrm{E}+17$ & $\begin{array}{l}\text { Atom 78- } \\
\text { Atom } 67\end{array}$ & -0.001047 & -0.001899 & $-1.26797 \mathrm{E}+17$ \\
\hline $\begin{array}{c}\text { Atom 60- } \\
\text { Atom53 }\end{array}$ & -0.00013 & 0.000213 & $1.42459 \mathrm{E}+16$ & $\begin{array}{l}\text { Atom 71- } \\
\text { Atom } 70\end{array}$ & -0.004524 & -0.003461 & $-2.31075 \mathrm{E}+17$ \\
\hline $\begin{array}{l}\text { Atom 121- } \\
\text { Atom } 114\end{array}$ & -0.001012 & -0.002792 & $-1.85095 \mathrm{E}+17$ & $\begin{array}{l}\text { Atom 20- } \\
\text { Atom 1 }\end{array}$ & 0.01917 & 0.047153 & $3.14007 \mathrm{E}+18$ \\
\hline $\begin{array}{c}\text { Atom 136- } \\
\text { Atom 115 }\end{array}$ & -0.016153 & -0.061738 & $-4.12166 \mathrm{E}+18$ & $\begin{array}{l}\text { Atom 38- } \\
\text { Atom } 24 \\
\end{array}$ & 0.001128 & -0.001435 & $-1.98419 \mathrm{E}+16$ \\
\hline $\begin{array}{l}\text { Atom 25- } \\
\text { Atom } 4\end{array}$ & 0.016365 & 0.061404 & $4.09939 \mathrm{E}+18$ & $\begin{array}{l}\text { Atom 90- } \\
\text { Atom } 80\end{array}$ & 0.000146 & -0.017473 & $-1.16614 \mathrm{E}+18$ \\
\hline $\begin{array}{l}\text { Atom 95- } \\
\text { Atom88 }\end{array}$ & -0.000061 & -0.000062 & $-4.14516 \mathrm{E}+15$ & $\begin{array}{l}\text { Atom 98- } \\
\text { Atom 93 }\end{array}$ & -0.002693 & -0.001574 & $-2.07089 \mathrm{E}+16$ \\
\hline $\begin{array}{l}\text { Atom 134- } \\
\text { Atom } 127\end{array}$ & -0.003173 & -0.007945 & $-5.32255 \mathrm{E}+17$ & $\begin{array}{l}\text { Atom 60- } \\
\text { Atom } 41\end{array}$ & 0.001456 & 0.001554 & $1.03684 \mathrm{E}+17$ \\
\hline
\end{tabular}


Zero-point energy $\left(\mathrm{E}_{\mathrm{ZPE}}\right)$, total correction energy $\left(\mathrm{E}_{\mathrm{TOT}}\right)$, enthalpy $\left(\mathrm{H}_{\mathrm{corr}}\right)$ and free gibs energy $\left(\mathrm{G}_{\mathrm{corr}}\right)$ value demonstrated in table3, as it shown below the most value of these parameters specified for Dopammine+7.5(nm) SWCNT and for Serotonin+7.5 (nm) SWCNT and respectively are equal with:
EZPE (Dopamine): 1.77
$\mathrm{E}_{\mathrm{ZPE} \text { (Serotonin): } 1.8}$
$\mathrm{E}_{\text {TOT (Dopamine) }}: 1.83$
$\mathrm{E}_{\mathrm{TOT}(\text { Serotonin): }}: 1.86$
$\mathrm{H}_{\text {corr (Dopamine) }}: 1.83$
$\mathrm{H}_{\text {corr (Serotonin) }: 1.86}$
$\mathrm{G}_{\text {corr (Dopamine) }}: 1.69$
$\mathrm{G}_{\text {corr (Serotonin): }} 1.72$

Potential difference energy and atomic charge energy of Dopamine and Serotonin complex listed in table 4-5 and according to the table 4, in Dopamine connected to SWCNT (7.0 nm diameter) complex $\mathrm{C}_{37-\mathrm{C}_{35}}$ has the most value of $\Delta \mathrm{V}(0.014)$ and $\mathrm{C}_{98}-\mathrm{C}_{23}$ has the most value of $\Delta \mathrm{q}(-0.014)$.In Dopamine connected to SWCNT (7.5 nm diameter) complex $\mathrm{C}_{131}-\mathrm{C}_{36}$ has the most value of $\Delta \mathrm{V}(0.004)$ and $\mathrm{C}_{72}-\mathrm{C}_{56}$ has the most value of $\Delta q(-0.003)$.For Dopamine connected to SWCNT (7.7 nm diameter) complex $\mathrm{C}_{25}-\mathrm{C}_{4}$ has the most value of $\Delta \mathrm{V}(0.016)$ and $\mathrm{C}_{136}-\mathrm{C}_{15}$ has the most value of $\Delta \mathrm{q}(-0.06)$ and In Dopamine connected to SWCNT (10.0 nm diameter) complex $\mathrm{C}_{20}-\mathrm{C}_{1}$ has the most value of $\Delta \mathrm{V}(0.019)$ and $\mathrm{C}_{90}-\mathrm{C}_{80}$ has the most value of $\Delta \mathrm{q}$ $(-0.017)$.

Based on table 5 ,in Serotonin connected to SWCNT (7.0 nm diameter) complex $\mathrm{C}_{84}-\mathrm{C}_{38}$ has the most value of $\Delta \mathrm{V}(0.02)$ and $\mathrm{C}_{101}-\mathrm{C}_{85}$ has the most value of $\Delta \mathrm{q}(-0.04)$.In Serotonin connected to SWCNT (7.5 nm diameter) complex $\mathrm{C}_{125}-\mathrm{C}_{44}$ has the most value of $\Delta \mathrm{V}(0.15)$ and $\mathrm{C}_{33}-\mathrm{C}_{31}$ has the most value of $\Delta \mathrm{q}$ (-0.07).For Serotonin connected to SWCNT (7.7 nm diameter) complex $\mathrm{C}_{17}-\mathrm{C}_{11}$ has the most value of $\Delta \mathrm{V}(0.015)$ and $\mathrm{C}_{114}-\mathrm{C}_{107}$ has the most value of $\Delta \mathrm{q}(-0.01)$ and In Serotonin connected to SWCNT (10.0 nm diameter) complex $\mathrm{C}_{54}-\mathrm{C}_{48}$ has the most value of $\Delta \mathrm{V}(29.0)$ and $\mathrm{C}_{94}-\mathrm{C}_{84}$ has the most value of $\Delta \mathrm{q}(-0.047)$.

Table5.Merz-Kollman parameters analyses of Serotonin +SWCNT carbon atoms in BLYP3/3-61(d) level of theory

\begin{tabular}{|c|c|c|c|c|c|c|c|}
\hline \multicolumn{4}{|c|}{ Serotonin +7.0 nm SWCNT } & \multicolumn{4}{|c|}{ Serotonin $+7.5 \mathrm{~nm}$ SWCNT } \\
\hline Atomic label & $\Delta \mathrm{V}=(\mathrm{V} 2-\mathrm{V} 1)$ & $\Delta q$ & $\Delta \mathrm{V}=(\mathrm{k}(\mathrm{q} 2-\mathrm{q} 1) / \mathrm{R} 21)$ & Atomic label & $\Delta \mathrm{V}=(\mathrm{V} 2-\mathrm{V} 1)$ & $\Delta q$ & $\Delta \mathrm{V}=(\mathrm{k}(\mathrm{q} 2-\mathrm{q} 1) / \mathrm{R} 21)$ \\
\hline $\begin{array}{l}\text { Atom95- } \\
\text { Atom 79 }\end{array}$ & 0.020936 & 0.023892 & $1.4059 \mathrm{E}+18$ & $\begin{array}{l}\text { Atom 59- } \\
\text { Atom } 44\end{array}$ & 0.00212 & 0.072666 & $4.65404 \mathrm{E}+18$ \\
\hline $\begin{array}{l}\text { Atom } 84- \\
\text { Atom } 38\end{array}$ & 0.027323 & 0.003392 & $6.02589 \mathrm{E}+16$ & $\begin{array}{l}\text { Atom 70- } \\
\text { Atom 69 }\end{array}$ & 0.00064 & 0.000821 & $5.23539 \mathrm{E}+16$ \\
\hline $\begin{array}{l}\text { Atom 78- } \\
\text { Atom } 62\end{array}$ & 0.008191 & 0.003824 & $2.25269 \mathrm{E}+17$ & $\begin{array}{l}\text { Atom 137- } \\
\text { Atom } 43\end{array}$ & 0.008244 & 0.001325 & $1.69242 \mathrm{E}+16$ \\
\hline $\begin{array}{l}\text { Atom 101- } \\
\text { Atom } 85\end{array}$ & -0.014437 & -0.041175 & $-2.45136 \mathrm{E}+18$ & $\begin{array}{l}\text { Atom 33- } \\
\text { Atom } 31\end{array}$ & -0.039698 & -0.071583 & $-4.56231 \mathrm{E}+18$ \\
\hline $\begin{array}{l}\text { Atom } 105- \\
\text { Atom } 103\end{array}$ & -0.003069 & 0.019313 & $1.14173 \mathrm{E}+18$ & $\begin{array}{l}\text { Atom 43- } \\
\text { Atom } 27\end{array}$ & -0.000042 & -0.001991 & $-1.26979 \mathrm{E}+17$ \\
\hline $\begin{array}{l}\text { Atom } 41- \\
\text { Atom } 39\end{array}$ & -0.003487 & 0.01977 & $1.17218 \mathrm{E}+18$ & $\begin{array}{l}\text { Atom 51- } \\
\text { Atom } 36\end{array}$ & 0.002899 & 0.01377 & $8.82197 \mathrm{E}+17$ \\
\hline $\begin{array}{l}\text { Atom 78- } \\
\text { Atom } 33\end{array}$ & -0.003959 & -0.003122 & $-5.09644 \mathrm{E}+16$ & $\begin{array}{l}\text { Atom } 87- \\
\text { Atom } 71\end{array}$ & -0.002846 & -0.003596 & $-2.2931 \mathrm{E}+17$ \\
\hline $\begin{array}{l}\text { Atom } 102- \\
\text { Atom } 13\end{array}$ & -0.000746 & 0.016571 & 9.82742 & $\begin{array}{l}\text { Atom 125- } \\
\text { Atom } 44\end{array}$ & 0.015214 & 0.002927 & 3.2058 \\
\hline $\begin{array}{c}\text { Atom } 24- \\
\text { Atom } 8\end{array}$ & 0.014363 & 0.016136 & 9.53403 & $\begin{array}{l}\text { Atom 16- } \\
\text { Atom 14 }\end{array}$ & 0.003046 & -0.000785 & +16 \\
\hline $\begin{array}{l}\text { Atom 55- } \\
\text { Atom 43 }\end{array}$ & -0.00887 & 0.012785 & 7.565 & $\begin{array}{l}\text { Atom 112- } \\
\text { Atom } 49\end{array}$ & -0.0 & 0.068997 & $7.63021 \mathrm{E}+17$ \\
\hline \multicolumn{4}{|c|}{ Serotonin $+7.7 \mathrm{~nm}$ SWCNT } & \multicolumn{4}{|c|}{ Serotonin $+10.0 \mathrm{~nm} \mathrm{SWCNT}$} \\
\hline Atomic label & $\Delta \mathrm{V}=(\mathrm{V} 2-\mathrm{V} 1)$ & $\Delta q$ & $\Delta \mathrm{V}=(\mathrm{k}(\mathrm{q} 2-\mathrm{q} \mathrm{l}) / \mathrm{R} 21)$ & Atomic label & $\Delta \mathrm{V}=(\mathrm{V} 2-\mathrm{V} 1)$ & $\Delta q$ & $\Delta \mathrm{V}=(\mathrm{k}(\mathrm{q} 2-\mathrm{q} 1) / \mathrm{R} 21)$ \\
\hline $\begin{array}{l}\text { Atom37- } \\
\text { Atom } 15\end{array}$ & -0.002547 & 0.013943 & $9.28641 \mathrm{E}+17$ & $\begin{array}{l}\text { Atom } 64- \\
\text { Atom } 54\end{array}$ & -29.093429 & -0.000513 & $-3.4306 \mathrm{E}+16$ \\
\hline $\begin{array}{l}\text { Atom 58- } \\
\text { Atom 51 }\end{array}$ & -0.001182 & -0.000613 & $-4.09662 \mathrm{E}+16$ & $\begin{array}{l}\text { Atom 24- } \\
\text { Atom } 14\end{array}$ & -0.001222 & 0.012735 & $8.5139 \mathrm{E}+17$ \\
\hline $\begin{array}{l}\text { Atom 108- } \\
\text { Atom } 101\end{array}$ & -0.000326 & -0.00021 & $-1.3975 \mathrm{E}+16$ & $\begin{array}{l}\text { Atom 54- } \\
\text { Atom } 48\end{array}$ & 29.09457 & 0.00107 & $1.4844 \mathrm{E}+16$ \\
\hline $\begin{array}{l}\text { Atom 17- } \\
\text { Atom } 11\end{array}$ & 0.015898 & 0.061568 & $4.11071 \mathrm{E}+18$ & $\begin{array}{l}\text { Atom 94- } \\
\text { Atom } 84\end{array}$ & -0.019428 & -0.047381 & $-3.15734 \mathrm{E}+18$ \\
\hline $\begin{array}{l}\text { Atom 106- } \\
\text { Atom 99 }\end{array}$ & 0.000272 & 0.000334 & $2.22229 \mathrm{E}+16$ & $\begin{array}{l}\text { Atom 69- } \\
\text { Atom 52 }\end{array}$ & -0.001998 & -0.001771 & $-2.65049 \mathrm{E}+16$ \\
\hline $\begin{array}{l}\text { Atom 80- } \\
\text { Atom } 73\end{array}$ & -0.000132 & 0.000182 & $1.21748 \mathrm{E}+16$ & $\begin{array}{l}\text { Atom 36- } \\
\text { Atom } 25\end{array}$ & 0.002073 & 0.002912 & $1.94438 \mathrm{E}+17$ \\
\hline $\begin{array}{l}\text { Atom } 27- \\
\text { Atom } 16\end{array}$ & 0.001942 & 0.000847 & $8.47164 \mathrm{E}+15$ & $\begin{array}{l}\text { Atom 8- } \\
\text { Atom } 4\end{array}$ & -0.001528 & -0.00115 & $-1.52978 \mathrm{E}+16$ \\
\hline $\begin{array}{l}\text { Atom 114- } \\
\text { Atom } 107\end{array}$ & 0.00326 & -0.010612 & $-7.0728 \mathrm{E}+17$ & $\begin{array}{l}\text { Atom 32- } \\
\text { Atom 31 }\end{array}$ & 0.0091 & 0.017025 & $6.73366 \mathrm{E}+17$ \\
\hline $\begin{array}{l}\text { Atom } 81- \\
\text { Atom } 60\end{array}$ & -0.000004 & 0.00007 & $4.68155 \mathrm{E}+15$ & $\begin{array}{l}\text { Atom 62- } \\
\text { Atom } 51\end{array}$ & -0.000238 & -0.002146 & $-7.28257 \mathrm{E}+16$ \\
\hline $\begin{array}{l}\text { Atom 29- } \\
\text { Atom 22 }\end{array}$ & -0.014864 & -0.014207 & $-9.50012 \mathrm{E}+17$ & $\begin{array}{l}\text { Atom 89- } \\
\text { Atom } 73\end{array}$ & -0.005511 & -0.017111 & $-2.17137 \mathrm{E}+17$ \\
\hline
\end{tabular}




\section{CONCLUSION}

In this work, we theoretically investigated the structure features of Dopamine and Serotonin as a biological active compound and single-walled carbon nanotube as a biological transfer. Chemical shift anisotropy asymmetry $(\eta)$, isotropy ( $\sigma$ iso), anisotropy ( $\sigma$ aniso), $\Delta \sigma, \mathrm{K}$ and chemical shift tensor $(\delta)$ were calculated based on theoretical data obtained from BL3Y/6-31G(d) levels of theory. Moreover, thermodynamic analyses with uff/6-31 G basis set were performed and then stabilization energies such as Zero-point energy, total correction, enthalpy and free Gibs energy and also Merz-Kollman Singh (MK) analysis carried out by gaussian 09 application.

\section{REFERENCES}

Berger, M.; Gray, J.A.; Roth, B.L. (2009) The expanded biology of serotonin. Annu Rev Med, 60, 355-66. doi: 10.1146/annurev.med.60.042307.110802.

Berridge, K.C.; Robinson, T.E.; Aldridge, J.W. (2009) Dissecting components of reward: 'liking', 'wanting', and learning. Current Opinion in Pharmacology, 9, 65-73. doi:10.1016/j.coph.2008.12.014. PMC 2756052. PMID 19162544.

Besler, B.H.; Merz, K.M.; Kollman P.A. (1990) Atomic Charges Derived from Semiempirical Methods, J. comp. Chem.,11,431-439.

Boyer, H.T. (1970) Quantum zero-point energy and long-range forces, Annals of physics, 56, 474-503. Doi: 10.1016/0003-4916(70)90027-8

Brami-Cherrier, K.; Valjent, E.; Garcia, M.; Pages, C.; Hipskind, R.A.; Caboche, J. (2002) Dopamine induces a PI3-kinase-independent activation of Akt in striatal neurons: a new route to cAMP response elementbinding protein phosphorylation. Journal of Neurosci, 22, 8911-8921

Bultinck, P.; Langenaeker, W.; Lahorte, P.; Proft, F.D.; Geerlings, P.; Alsenoy, C.V.; Tollenaere, J.P. (2002) The Electronegativity Equalization Method II: Applicability of Different Atomic Charge Schemes, J Phys Chem A, 106, 7895-7908.

Conn, P.J.; Sanders-Bush, E. (1984) Selective 5-HTe antagonists inhibit serotonin stimulated phosphatidylinositol metabolism in cerebral cortex, Neuropharmacology, 23, 993-996.

Conn, P.J.; Sanders-Bush, E. (1986) Agonist-induced phosphoinositide hydrolysis in choroid plexus, J. Neurochem., 47, 1754-1760.

Dang, D.M.T.; Monajjemi, M.; Mollaamin, F.; Dang, C.M. (2020) Simulation of droplet ejection based on electromechanical parameters \& chemical condition for controlling inkjet printing devices Biointerface Research in Applied chemistry, 10, 5361-5368. https://doi.org/10.33263/BRIAC103.361368

Deutch, A.Y.; Roth, R.H.; (1999) Neurotransmitters. In Fundamental Neuroscience, Academic Press 193234 ,

Dickson, D.V. (2007) Neuropathology of movement disorders, In Tolosa E, Jankovic JJ (eds.). Parkinson's disease and movement disorders. Hagerstown, MD: Lippincott Williams \& Wilkins, 271-83. ISBN 978-07817-7881-7. 
Endo, Y.; Shibazaki, M.; Nakamura, M.; Takada, H. (1997) Contrasting effects of lipopolysaccharides (endotoxins) from oral black-pigmented bacteria and Enterobacteriaceae on platelets, a major source of serotonin, and on histamine-forming enzyme in mice, J Infect Dis, 175, 1404-12. doi:10.1086/516473

Facelli, J.C. (2002) Encyclopedia of Nuclear Magnetic Resonance; D. M. Grant, R. K. Harris, Eds., London: John Wiley \& Sons., 9, 323.

Herr, N.; Bode, C.; Duerschmied, D. (2017) The effects of Serotonin in immune Cells, Front. Cardiovasc. Med, 20, 48. doi.org/10.3389/fcvm.2017.00048.

Hopper, T.; Mandal, S.; David, C.; Hürlimann, M.; Yi-Qiao, S. (2011) Low-frequency NMR with a nonresonant circuit, Journal of Magnetic Resonance, 210, 69-74. Doi: 10.1016/j.jmr.2011.02.014

Howes, O.D; Kapur, S. (2009) The dopamine hypothesis of schizophrenia: version III-the final common pathway, Schizophrenia Bulletin, 35, 549-62. doi:10.1093/schbul/sbp006. PMC 2669582. PMID 19325164.

Hoyer, D. (1988) Molecular pharmacology and biology of 5-HT 1 C receptors, Trends Pharmacol. Sci., 9, 89-94.

Joohari, S.; Monajjemi, M. (2015) NMR and NBO study of vinblastine as a biological inhibitor.; Bulgarian Chemical Communications, 47, 631-646.

Julius, D.; MacDermott, A.B.; Axel, R.; Jesse, T. (1988) Molecular characterization of a functional cDNA encoding the serotonin lc receptor, Science, 241, 558-564

Kienast, T.; Heinz, A. (2006) Dopamine and the diseased brain. CNS Neurol Disord Drug Targets, 5, 10931.

Le, C.M.T.; Mollaamin, F.; Dang, D.M.T.; Monajjemi, M.; Dang, C.M. (2019) Realistic simulation of the polymers in inkjet process: the investigation of physical phenomena in the ejection of a droplet, Biointerface Research in Applied chemistry, 9, 3949-3955. https://doi.org/10.33263/BRIAC93.949955

Le, C.M.T.; Monajjemi, M.; Pham, T.T.; Mollaamin, F.; Dang, C.M. (2020) Diffusion \& concentration effect of $\mathrm{Li} / \mathrm{Li}+$ to the efficiency of LIBs, Biointerface Research in Applied chemistry, 10, 5076-5084. https://doi.org/10.33263/BRIAC102.076084

Le, C.M.T.; Monajjemi, M.; Pham, T.T.; Mollaamin, F.; Dang, C.M. (2019), Simulation \& modelling of dilute solutions in drop-on-demand inkjet printing: a review, Biointerface Research in Applied chemistry, 9, 4474 - 4484, https://doi.org/10.33263/BRIAC96.474484

Lindemann. L.; Hoener, M.C. (2005) A renaissance in trace amines inspired by a novel GPCR family, Trends Pharmacol. Sci. 26, 274-281. doi:10.1016/j.tips.2005.03.007. PMID 15860375

Menegon, G.; Shimizu, K.; Farah, J.P.S.; Dias, L.G.; Chaimovich, H. (2002) Parameterization of the electronegativity equalization method based on the charge model 1, Phys Chem Chem Phys, 4, 5933-5936.

Miller, G.M. (2011) The emerging role of trace amine-associated receptor 1 in the functional regulation of monoamine transporters and dopaminergic activity, Journal of Neurochemistry, 116, 164-76. doi:10.1111/j.1471-4159.2010.07109.x. $\quad$ PMC $3005101 . \quad$ PMID 21073468 https://draxe.com/health/dopamine/

Mollaamin, F.; Pham, T.T.; Dang, D.M.T.; Monajjemi, M.; Dang, C.M. (2019) Modelling and Controlling of ion transport rate efficiency in Proton exchange membrane (PEMFC), alkaline (AFC), direct methanol 
(DMFC), phosphoric acid (PAFC), direct forming acid(DFAFC) and direct carbon (DCFC) fuel cells, Biointerface Research in Applied chemistry, 9, 4050-4059. https://doi.org/10.33263/BRIAC94.050059

Monajjemi, M. (2019), Artificial intelligence \& self-consistent sonification method for converting DNA sequence to music, Biointerface Research in Applied chemistry, 9, 4494-4501, https://doi.org/10.33263/BRIAC96.494501

Monajjemi, M. (2019) C-NMR sonification of human insulin: a method for conversion of amino-acid sequences to music notes, Biointerface Research in Applied chemistry, 9, 4077-4084. https://doi.org/10.33263/BRIAC94.077084

Monajjemi, M. (2019) Molecular vibration of dopamine neurotransmitter: a relation between its normal modes and harmonic notes, Biointerface Research in Applied chemistry, 9, 3956-3962. https://doi.org/10.33263/BRIAC93.956962

Monajjemi, M., (2019) Molecular biology's symphony orchestra from DNA to ribosome: a sonification from gene to protein, Biointerface Research in Applied chemistry, 10, 5679-5688. https://doi.org/10.33263/BRIAC104.679688

Monajjemi, M.; Mollaamin, F.; Shojaei, S. (2020) An overview on Coronaviruses family from past to Covid-19: introduce some inhibitors as antiviruses from Gillan's plants, Biointerface Research in Applied chemistry, 10, 5575-5585. https://doi.org/10.33263/BRIAC103.575585

Monajjemi, M.; Naghsh, F.; Mollaamin, F. (2020) Bio-Lipid Nano Capacitors: Resonance with Helical Myeline Proteins, Biointerface Research in Applied chemistry, 10, 6695-6705. https://doi.org/10.33263/BRIAC106.66956705

Monajjemi, M.; Mollaamin, F. (2020) Bio-capacitor consist of insulated myelin-sheath and uninsulated node of Ranvier: a bionano-antenna, Biointerface Research in Applied chemistry, 10, 4956-4965. https://doi.org/10.33263/BRIAC101.956965

Monajjemi, M.; Shahriari, S.; Mollaamin, F. (2020) Evaluation of Coronavirus Families \& Covid-19 Proteins: Molecular Modeling Study, Biointerface Research in Applied chemistry, 10, 6039-6057. https://doi.org/10.33263/BRIAC105.60396057

Mössner, R.; Lesch, K.P. (1998) Role of serotonin in the immune system and in neuroimmune interactions, Brain Behav Immun, 12, 249-71. doi:10.1006/ brbi.1998.0532

Naghsh, F.; Monajjemi, M.; Zare, K. (2018) A conceptual model of microtubules as a macrobiological molecule and Quantum Consciousness, Biointerface Research in Applied chemistry, 8, 3758 - 3763.

Pantarotto, D.; Singh, R.; McCarthy, D.; Erhardt, M.; Briand, J.P.; Prato, M. et al. (2004). Functionalized carbon nanotubes for plasmid DNA gene delivery, Angew. Chem. Int. Ed., 43, 5242-5246. doi: 10.1002/anie.200460437

Peroutka, S.J. (1990) 5-Hydroxytryptamine receptor subtypes, Pharmacol. Toxicol., 67, 373-383.

Pham, T.T.; Monajjemi, M.; Dang, D.M.T.; Mollaamin, F.; Dang, C.M. (2019) Reaction of cell membrane bilayers "as a variable capacitor" with G-protein: a reason for neurotransmitter signaling, Biointerface Research in Applied chemistry, 9, 3874-3883. https://doi.org/10.33263/BRIAC92.874883 
Pham, T.T.; Monajjemi, M.; Dang, D.M.T.; Mollaamin, F.; Dang, C.M. (2019) Nano-capacitors as batteries including graphene electrodes and Ga-N mixed with biopolymers as insulator, Biointerface Research in Applied chemistry, 9, 3806-3811. https://doi.org/10.33263/BRIAC91.806811

Pham, T.T.; Monajjemi, M.; Dang, D.M.T.; Mollaamin, F.; Khakpour, A.; Dang, C.M. (2019) An overview of bio-interface electrolyte and Li2FePO4F as cathode in Li-ion batteries, Biointerface Research in Applied chemistry, 9, 3866 - 3873. https://doi.org/10.33263/BRIAC92.866873

Pham, T.T.; Monajjemi, M.; Mollaamin, F.; Dang, C.M. (2020) Advanced materials for family of fuel cells: a review of polymer electrolyte membrane, Biointerface Research in Applied chemistry, 10, 4853 - 4863. https://doi.org/10.33263/BRIAC101.853863

Reed, A.E.; Curtiss, L.A.; Weinhold, F. (1988) Intermolecular Interactions from a Natural Bond Orbital, Donor-Acceptor Viewpoint, Chem. Rev., 88, 899-926.

Robinson, T.E.; Berridge, K.C. (1993) The neural basis of drug craving: an incentive-sensitization theory of addiction, Brain Research. Brain Research Reviews, 18, 247-91. doi:10.1016/0165-0173(93)90013-p. PMID 8401595

Romanelli, R.J.; Williams, J.T.; Neve, K.A. (2009) Chapter 6: Dopamine receptor signalling: intracellular pathways to behavior, In Neve KA (ed.). The Dopamine Receptors. Springer. 137-74. ISBN 978-1-60327$333-6$.

Singh, U.C.; Kollman, P.A. (1984) An approach to computing electrostatic charges for molecules, J Comput Chem, 5, 129-145.

Tîlmaciu, C.M.; May C.; Morris, M.C. (2015) Carbon nanotube biosensors; Frontiers in Chemistry, 3, 121. doi:10.3389/fchem.2015.00059

Vanderschuren, L.J.; Kalivas, P.W. (2000) Alterations in dopaminergic and glutamatergic transmission in the induction and expression of behavioral sensitization: a critical review of preclinical studies. Psychopharmacol Ber, l 151, 99-120.

Wagner, D.D.; Frenette, P.S. (2008) The vessel wall and its interactions, Blood, 111, 5271-81. doi:10.1182/blood-2008-01-078204

Wang, X. et al. (2019) The Prospective Value of Dopamine Receptors on Bio-Behavior of Tumor, Journal of Cancer, 10, 1622-1632. doi:10.7150/jca.27780.PMCID.PMC6548012

Wise, R.A. (2004) Dopamine, Learning and Motivation, Nature reviews Neuroscience, 5, 483-494. doi:10.1038/nrn1406

Xiangdang, S.; McGinty, J.F. (2010) D1 and D2 dopamine receptors differentially mediate the activation of phosphoproteins in the striatum of amphetamine-sensitized rats, Psychopharmacology, 214, 653-63. DOI 10.1007/s00213-010-2068-4.

Yu, B.; Becnel, J.; Zerfaoui, M.; Rohatgi, R.; Boulares, A.H.; Nichols, C.D. (2008) Serotonin 5hydroxytryptamine(2A) receptor activation suppresses tumor necrosis factor-alpha-induced inflammation with extraordinary potency, J Pharmacol Exp Ther, 327, 316-23. doi:10.1124/jpet.108.143461

Zhu, H.W.; Xu, C.L.; Wu, D.H.; Wei, B.Q.; Vajtai, R.; Ajayan, P. M. (2002) Direct synthesis of long singlewalled carbon nanotube strands, Science, 296, 884-886. doi: 10.1126/science.1066996. 